\title{
Ultrastructural Changes in the Cell Wall of Candida albicans Following Cessation of Growth and their Possible Relationship to the Development of Polyene Resistance
}

\author{
By A. CASSONE,* D. KERRIDGE AND E. F. GALE \\ Sub-Department of Chemical Microbiology, Department of Biochemistry, \\ Tennis Court Road, Cambridge CB2 $1 Q W$
}

(Received 18 July 1978)

\begin{abstract}
The ultrastructure of the wall of Candida albicans strain 6406 was examined in polyeneresistant organisms obtained by continued incubation after the cessation of growth. The walls of organisms harvested either during the exponential phase of growth or after $24 \mathrm{~h}$ starvation, when examined in situ, showed the typical layered appearance. After $72 \mathrm{~h}$ starvation, when the resistance to amphotericin B methyl ester (AME) was 60 times greater than that of exponentially growing organisms, both the periplasmic material and the distinct electron-dense layers were absent from the wall. At this stage there was no increase in the thickness of the wall. After $144 \mathrm{~h}$ starvation the thickness of the wall had increased from $143 \pm 22 \mathrm{~nm}$ (exponential phase organisms) to $211 \pm 58 \mathrm{~nm}$. If after $144 \mathrm{~h}$ starvation the organisms were incubated for $1 \mathrm{~h}$ in fresh nutrient medium they regained their sensitivity to AME and the wall regained the periplasmic material and its characteristic multilayered appearance. During the first $24 \mathrm{~h}$ starvation there was a considerable fall in the soluble glucan fraction, but on continued incubation there was little change in the relative proportions of the major carbohydrate constituents of the cell. Thin sections of purified walls isolated from organisms harvested either during exponential growth or after $144 \mathrm{~h}$ starvation were identical in appearance and characterized by the absence of the electrondense layers observed in sections of intact cells and by a reduction in thickness to $100 \pm$ $20 \mathrm{~nm}$.
\end{abstract}

\section{INTRODUCTION}

Candida albicans strain 6406 shows a marked phenotypic variation in its sensitivity to the polyene antibiotics (Gale et al., 1975; Johnson et al., 1978). These changes in antibiotic sensitivity are particularly pronounced in the organism after the cessation of growth when the minimum inhibitory concentration (determined by following $\mathrm{K}^{+}$release) may be two orders of magnitude greater than that of exponentially growing organisms (Gale et al., 1975; Gale et al., 1977). This change in antibiotic sensitivity is apparently associated with modifications of the wall since protoplasts prepared from resistant cells harvested during the stationary phase of growth have a sensitivity to amphotericin B methyl ester (AME) comparable to that of organisms harvested during the exponential phase of growth (Gale et al., 1975). The wall of C. albicans is a complex structure both chemically and structurally (Chattaway et al., 1968; Cassone et al., 1973; Poulain et al., 1978) and these studies were undertaken to examine the structure of the wall after the cessation of growth and to attempt to correlate such changes with the increased resistance to AME.

* Permanent address: Institute of Microbiology, Medical Faculty, University of Rome, Rome, Italy. 


\section{METHODS}

Organism. The organism used throughout this study was Candida albicans strain 6406 obtained from $\mathrm{Dr}$ D. W. R. McKenzie, Mycological Reference Laboratory, London School of Hygiene and Tropical Medicine. It was maintained by weekly subculture in a liquid medium (YNBG) containing Difco Bacto yeast nitrogen base $\left(6 \cdot 7 \mathrm{~g}^{-1}\right)$ supplemented with $1 \%(\mathrm{w} / \mathrm{v})$ glucose.

Growth and incubation conditions. Organisms were grown in a 1 litre continuous flow fermenter (FL101, AB Biotec, Stockholm, Sweden) as described by Gale et al. (1977). The rate of stirring, supply of medium, aeration and temperature were controlled and monitored by the appropriate accessories (LP100 process instrumentation panel, AB Biotec). YNBG medium (1 litre) was inoculated with $C$. albicans and incubated aerobically (air flow $2.71 \mathrm{~min}^{-1}$ ) at $37{ }^{\circ} \mathrm{C}$ with the medium stirred at $1000 \mathrm{rev} . \mathrm{min}^{-1}$. After $16 \mathrm{~h}$, continuous flow of medium was started $\left(D=0 \cdot 15 \mathrm{~h}^{-1}\right)$ and continued for $36 \mathrm{~h}$; at this time the flow of medium was stopped but incubation was continued under the same conditions of temperature, aeration and stirring. Samples were withdrawn at $24 \mathrm{~h}$ intervals for determination of AME-induced $\mathrm{K}^{+}$release, examination by electron microscopy, cell fractionation and carbohydrate estimation.

Estimation of $K^{+}$release and $A M E$ sensitivity. Organisms were suspended at a final density of $1 \mathrm{mg}$ dry wt $\mathrm{ml}^{-1}$ in $0.03 \mathrm{M}$-Tris $/ \mathrm{HCl}$ buffer $\mathrm{pH} 7.5$ at $20^{\circ} \mathrm{C}$ and the rate of $\mathrm{K}^{+}$release induced by AME was estimated using a $\mathrm{K}^{+}$-sensitive electrode (Gale, 1974). The concentration of AME required to induce a rate of $\mathrm{K}^{+}$release equal to $1 \mathrm{nmol} \mathrm{min}^{-1}\left(\mathrm{mg}\right.$ dry wt) ${ }^{-1}$ above that in the control without $\mathrm{AME}$ in $8 \mathrm{~min}$ at $20^{\circ} \mathrm{C}$ was determined; this concentration is termed the standard release concentration (s.r.c.).

Cell breakage and fractionation. Washed organisms $(25 \mathrm{mg}$ dry wt) were resuspended in $1 \mathrm{ml}$ ice-cold distilled water and disrupted by vigorous vortex mixing (Whirlimixer; Scientific Industries International) for $2 \mathrm{~min}$ in the presence of glass beads $(0.45$ to $0.5 \mathrm{~mm}$ diam.). The walls were harvested by centrifuging and washed 10 times with ice-cold distilled water prior to carbohydrate assay and examination by electron microscopy.

Intact organisms or walls from an equivalent quantity of cells were fractionated into their major carbohydrate constituents by the method of Trevelyan \& Harrison (1956) as described by Herbert et al. (1971). Organisms ( $25 \mathrm{mg}$ dry wt), or walls from an equivalent amount of organisms, were resuspended in $0.5 \mathrm{M}-$ trichloroacetic acid and incubated at $0{ }^{\circ} \mathrm{C}$ for $1 \mathrm{~h}$. The cells were separated by centrifuging and the supernatant fluid containing the low molecular weight carbohydrates was retained. After extraction of the RNA from the pellet with $0.5 \mathrm{M}$-perchloric acid for $90 \mathrm{~min}$ at $38{ }^{\circ} \mathrm{C}$, the mannan and alkali-soluble glucan were extracted with $0 \cdot 25 \mathrm{M}-\mathrm{Na}_{2} \mathrm{CO}_{3}$ for $45 \mathrm{~min}$ at $100^{\circ} \mathrm{C}$. The alkali-soluble fraction was divided into two parts: one was used for determination of the total alkali-soluble carbohydrate and the other for determination of the mannan after precipitation as the insoluble mannan-copper complex following addition of $\mathrm{KOH}$ (final concentration $1 \mathrm{M}$ ) and Fehlings solution to the extract. The pellet after alkali extraction was further extracted with $0.5 \mathrm{M}$-perchloric acid for $30 \mathrm{~min}$ at $100^{\circ} \mathrm{C}$; this extract contained the acid-soluble glucan. The final residue was resuspended in $2 \mathrm{M}-\mathrm{NaOH}$ prior to carbohydrate assay.

The carbohydrate content of each fraction was assayed using the anthrone reagent as described by Herbert et al. (1971). Glucose standards were always included. The value for the mannan fraction was corrected for the lower absorbance $(55 \%)$ that this fraction gives relative to the glucose standard.

Electron microscopy. The standard procedure used to prepare samples for electron microscopy was as follows. Pelleted washed organisms or walls were fixed with a mixture of $0.5 \%(\mathrm{v} / \mathrm{v})$ glutaraldehyde and $1.0 \%(\mathrm{v} / \mathrm{v})$ acrolein in $0.075 \mathrm{M}$-phosphate buffer $\mathrm{pH} 7.2$ for $30 \mathrm{~min}$ at $4{ }^{\circ} \mathrm{C}$. This was followed by postfixation with $4 \%(\mathrm{w} / \mathrm{v})$ osmium tetroxide in water for $12 \mathrm{~h}$ at $4{ }^{\circ} \mathrm{C}$. The samples were stained 'en bloc' with $0.5 \%(\mathrm{w} / \mathrm{v})$ uranyl acetate in $0.5 \mathrm{M}$-veronal acetate buffer $\mathrm{pH} 5.4$ for $3 \mathrm{~h}$ at $4{ }^{\circ} \mathrm{C}$. All samples were dehydrated through a graded ethanol series, infiltrated with propylene oxide and embedded in Spurr's low-viscosity resin (Spurr, 1969). Sections were cut using a LKB Ultratome III equipped with a glass knife and, unless otherwise stated, were stained with lead citrate (Reynolds, 1963) for 30 min prior to examination in either an AEI 801 or a Siemens 1A electron microscope operating at 60 to $80 \mathrm{kV}$. Where other fixatives were used, details are given in the text.

Polysaccharides in isolated walls were detected by the cytochemical test of Thiery (1967) as applied to intact Candida cells by Cassone et al. (1972). The samples were fixed with either glutaraldehyde or osmium tetroxide since preliminary experiments had shown that the standard fixation procedure introduced a sufficient number of 'artefactual' aldehyde groups into control preparations to elicit a positive Thiéry reaction. The thin sections were oxidized with $1 \%(\mathrm{w} / \mathrm{v})$ periodic acid for $30 \mathrm{~min}$, washed with water and transferred to a solution of $0.5 \%(\mathrm{w} / \mathrm{v})$ thiosemicarbazide in $20 \%(\mathrm{v} / \mathrm{v})$ acetic acid for $60 \mathrm{~min}$. After thorough washing in a descending acetic acid series $(20,10,5,1 \%, \mathrm{v} / \mathrm{v})$ and finally water, the sections were mounted on uncoated grids and stained with $1 \%(\mathrm{w} / \mathrm{v})$ silver proteinate for $30 \mathrm{~min}$. In the control preparations either periodic acid or thiosemicarbazide was omitted. 
The thickness of the wall was obtained from measurements on $3 \times$ enlarged prints. For the measurements on intact cells, care was taken to measure only walls in nearly median section as judged by the appearance of the plasma membrane profile. This was not possible with the preparations of purified walls, and the values of the wall thickness in these preparations are an overestimate due to the presence of oblique sections. In some sections the thickness of the wall profile was different in different places; nevertheless a comparison of the relative mean values of different samples is justified. Approximately 100 wall profiles taken from different sections for each sample were measured and the results are expressed as the mean value \pm the standard deviation.

\section{RESULTS}

\section{Ultrastructure of the wall during exponential growth and subsequent starvation}

Organismis harvested from a culture of $C$. albicans growing exponentially in continuous culture, fixed with glutaraldehyde and osmium tetroxide and stained with lead citrate showed the usual multilayered appearance (Cassone et al., 1973), with outer electron-dense components and inner electron-transparent layers together with some partially electrondense granules within the wall (Fig. $1 a$ ). Scattered highly electron-opaque granules were present on the surface of the wall; these were absent from the cells harvested after $24 \mathrm{~h}$ starvation (Fig. $1 b$ ) and could be artefactual. There was a prominent periplasmic layer in both exponentially growing organisms and organisms which had been starved for $24 \mathrm{~h}$ and this closely followed the invaginations of the plasma membrane. The periplasmic layer was always detected in exponentially growing organisms, regardless of the nature of the fixative and the osmotic strength of the fixation mixture. The thickness of the wall in $C$. albicans harvested during exponential growth was $143 \pm 22 \mathrm{~nm}$ and after $24 \mathrm{~h}$ starvation, $144 \pm 26 \mathrm{~nm}$. The wall thickness was not significantly different after $72 \mathrm{~h}$ starvation (Fig. $1 a, b, c)$.

Major changes in the ultrastructure of the wall were observed in organisms which had been starved for prolonged periods (Fig. 1c,d). Most electron-dense outer components were absent, the overall structure appearing essentially electron-transparent with only a faint electron-dense line at the extreme periphery of the wall. The inner periplasmic layer was first greatly reduced and after prolonged starvation was absent. After prolonged starvation $(144 \mathrm{~h})$ the wall had a uniform electron-transparent structure with no layering of components and was considerably thicker than that of exponentially growing organisms, being $211 \pm 58 \mathrm{~nm}$.

There were no marked changes in the wall during the first $24 \mathrm{~h}$ starvation, during which time the s.r.c. [concentration of AME required to give a $\mathrm{K}^{+}$release of $1 \mathrm{nmol} \mathrm{min}-1$ (mg dry wt) $)^{-1}$ above the control rate] increased from 0.2 to $1.5 \mu \mathrm{g} \mathrm{AME} \mathrm{ml}^{-1}$. After $72 \mathrm{~h}$ starvation, when there were appreciable changes in the wall ultrastructure, the s.r.c. for AME had risen to $12 \mu \mathrm{g} \mathrm{ml}^{-1}$.

Other fixatives and stains, including permanganate and uranyl acetate, were used to detect changes in the organization of the wall during starvation. Despite the differences in the primary visualization observed using different fixatives and stains, the pattern of changes during starvation was comparable to those shown in Figs 1 and 2 . When the organisms were intensely stained, either 'en bloc' or in section with uranyl acetate, the walls of stationary phase organisms showed a variable amount of electron-dense components; but in contrast to the exponential phase organisms, these components were not layered but uniformly distributed throughout the wall. The over-staining effect of uranyl acetate was enhanced in organisms previously subjected to ultrasonic treatment for $10 \mathrm{~min}$ in a Dawe Sonicleaner (type 6441 A Dawe Instruments, London) (Fig. 2 and see below).

If after prolonged incubation in the stationary phase the organisms were resuspended in fresh nutrient medium (YNBG) and aerated at $37^{\circ} \mathrm{C}$, they quickly regained the wall configuration typical of exponentially growing organisms with electron-dense layers, an inner electron-transparent region and a dense periplasmic layer. Recovery began before the first cell division occurred and was clearly distinguishable after regrowth for $1 \mathrm{~h}$ (Fig. $1 e$ ). 

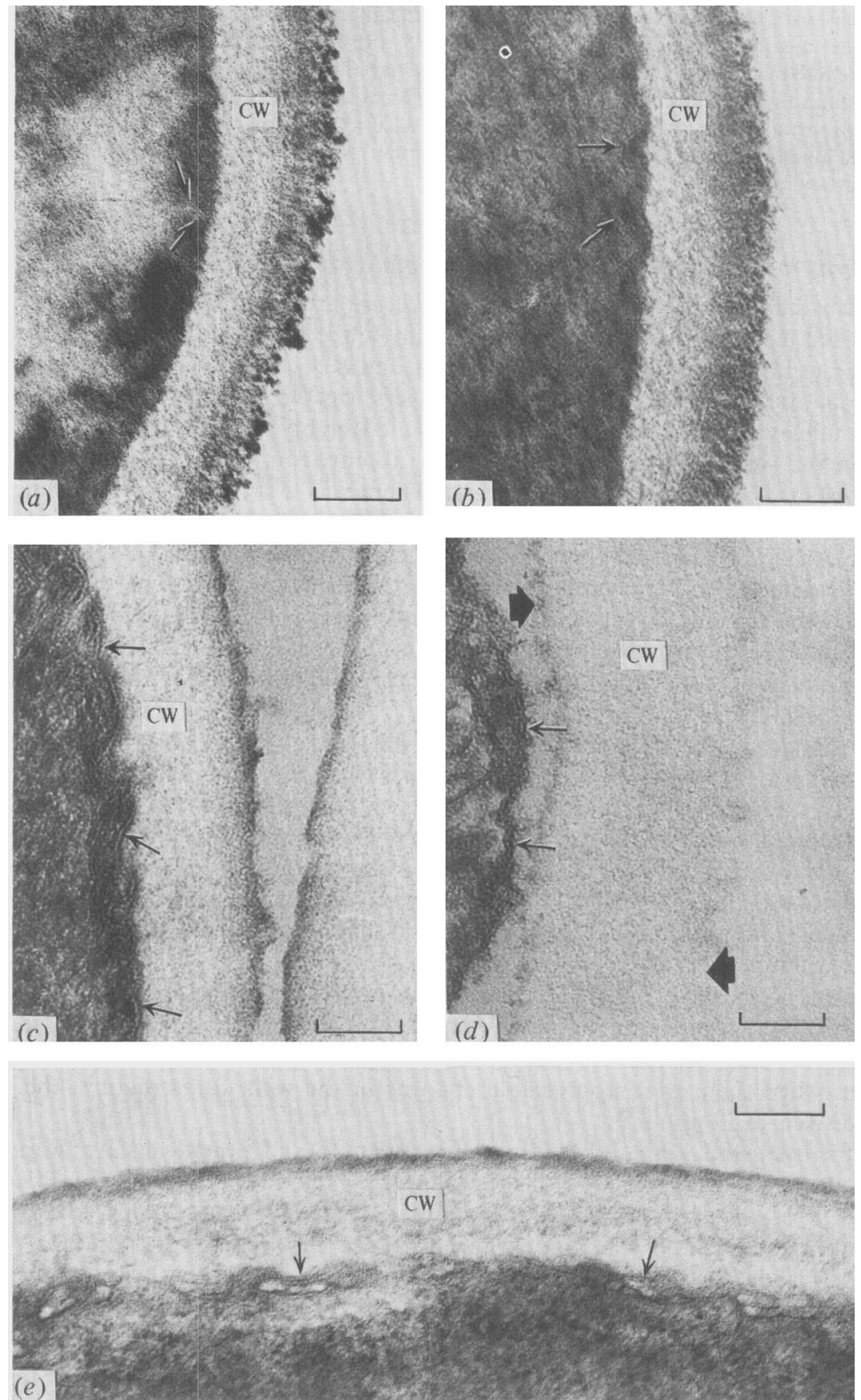

Fig. 1. Walls (CW) of Candida albicans in organisms harvested (a) from an exponentially growing culture, $(b)$ after $24 \mathrm{~h}$ incubation in the stationary phase, (c) after $72 \mathrm{~h}$ incubation in the stationary phase, $(d)$ after $144 \mathrm{~h}$ incubation in the stationary phase, (e) after incubation of organisms previously starved for $144 \mathrm{~h}$ in fresh nutrient medium for $1 \mathrm{~h}$. Note the significant increase in wall thickness from $(c)$ to $(d)$ and the recovery of the layered configuration of the oldest wall $(d)$ after regrowth $(e)$. Also the progressive thinning of the periplasmic layer and its absence from $(d)$; thin arrows indicate the plasma membrane. In $(d)$, the wall is delimited by the broad arrows. Sections stained with lead citrate for 30 min. Bar markers represent $100 \mathrm{~nm}$. 

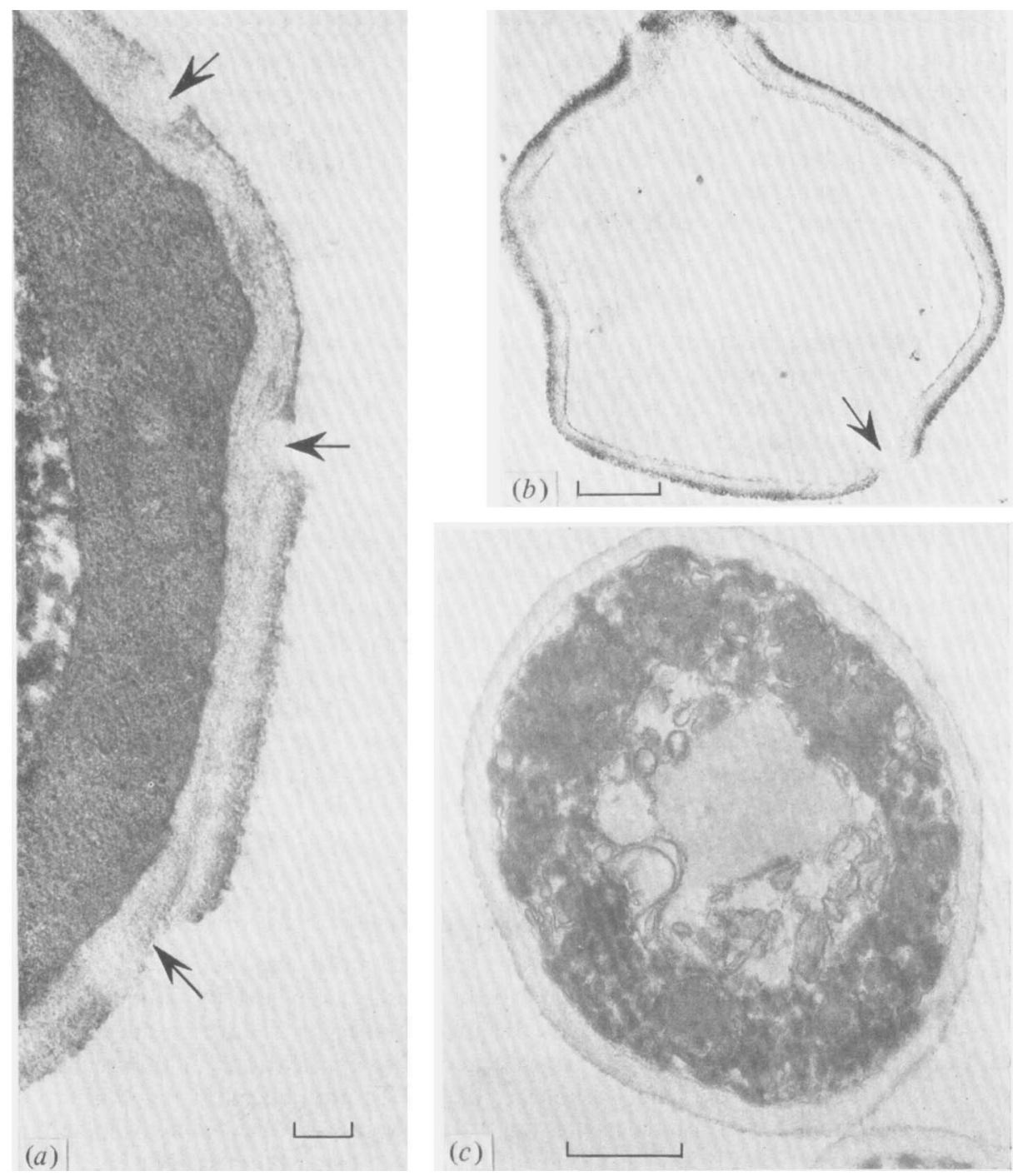

Fig. 2. Effect of ultrasonic treatment on exponential phase $(a, b)$ and stationary phase $(c)$ organisms. Discrete areas of wall breakage are arrowed in $(a)$ and $(b)$. Note that the 'isolated' wall in (b) maintains its layered organization. Sections heavily stained with lead citrate and uranyl acetate for $45 \mathrm{~min}(a)$ or $30 \mathrm{~min}(b, c)$. Bar markers represent $100 \mathrm{~nm}(a)$ or $500 \mathrm{~nm}(b, c)$.

The walls of organisms undergoing budding appeared to be identical to those shown in Fig. $1(a, b)$.

\section{Effect of ultrasonic treatment on wall structure}

Walls from exponentially growing and stationary phase organisms differed markedly in their response to ultrasonic treatment. A relatively mild ultrasonic treatment for $10 \mathrm{~min}$ in a Dawe Sonicleaner (type 6441A) was sufficient to break a small proportion of exponential phase organisms but stationary phase organisms were unaffected (Fig. 2). Breakage occurred at discrete, definite regions of the wall, presumably at the weakest points corresponding to the budding zones (Fig. $2 a$ ). If sufficient of the wall was broken, the cytoplasm still enclosed within the plasma membrane was seen to emerge leaving a 'clean' wall (Fig. 
$2 b$ ). The latter appeared to be similar to the wall of untreated organisms showing electrondense layered components. There was, however, a slight reduction in thickness to an average value of approximately $115 \mathrm{~nm}$. The walls of both exponential phase and stationary phase organisms were more easily stained with conventional heavy metal stains after ultrasonic treatment suggesting that even in the absence of cell breakage there were changes in wall polymers which exposed stainable end-groups. Apart from a direct effect of sonication on some molecular bonds, this could have resulted from a stimulation of lytic enzymes present in the wall with consequent partial degradation of the wall constituents.

\section{Ultrastructure of isolated walls}

A comparative ultrastructural analysis of isolated walls was undertaken to confirm the differences between exponential and stationary phase organisms and to correlate them with the chemical composition of the wall. Purified walls from organisms harvested during the exponential and stationary phases of growth had a uniformly electron-transparent appearance under the electron microscope regardless of the methods of fixation and staining employed (Fig. 3). The appearance was the same even when cytoplasmic remnants remained attached to the wall or the wall itself was not completely purified. Only in a few instances were thin, inconspicuous low-density components seen outlining the outer wall profile (Fig. 3). Layered electron-dense components could be preserved, to a limited extent, by fixing the organisms before breakage, but the purity of such preparations was very low, there being massive cytoplasmic contamination. Isolated walls from organisms harvested from both exponentially growing and stationary phase cultures were consistently thinner than their counterparts in intact cells. The measured thicknesses were: exponential phase cells, $101 \pm 20 \mathrm{~nm}$; stationary phase cells, $100 \pm 19 \mathrm{~nm}$. These values are, however, only approximate due to the sectioning effect and the observation that in the same wall profile some parts were thicker than others.

\section{Cytochemical detection of polysaccharides in isolated walls}

The organization of the constituents of the walls of both exponentially growing and stationary phase organisms was examined by the method devised by Thiéry (1967) for the cytological detection of polysaccharides. By this staining procedure mannan and 1,6- $\beta$ glucan, but not $1,3-\beta$-glucan or chitin, are detected. The applications of this technique to intact cells have been described by Cassone et al. (1972) and, recently, by Poulain et al. (1978) who confirmed the complex nature of wall layering in C. albicans. Isolated walls from both exponential phase and stationary phase organisms reacted intensely with the Thiéry stain giving a reproducible pattern of silver grains (Figs 4,5 ). In both wall preparations the reaction was strongest at the outer surface, but the outermost material was irregular and discontinuous and there was no precise separation into layers. In walls from exponentially growing organisms the staining reaction was less intense in the inner regions of the wall, the innermost part being almost unreactıve (Fig. $5 a$ ). This finding is consistent with the postulated abundance of 1,3- $\beta$-glucan and chitin in this region (Chattaway et al., 1976; Cassone et al., 1978; Poulain et al., 1978). In walls from organisms harvested from stationary phase cultures the staining reaction was strong and uniform across the wall, indicating a more uniform distribution of reactive and unreactive polysaccharides consistent with a greater intermixing of wall constituents in these organisms (Fig. $5 b, c$ ).

\section{Changes in the main carbohydrate fractions during growth and starvation}

Since electron microscopic examination had demonstrated considerable differences in the organization and structure of the wall of $C$. albicans following the onset of starvation, both when examined in situ and in isolated purified preparations, an attempt was made to 

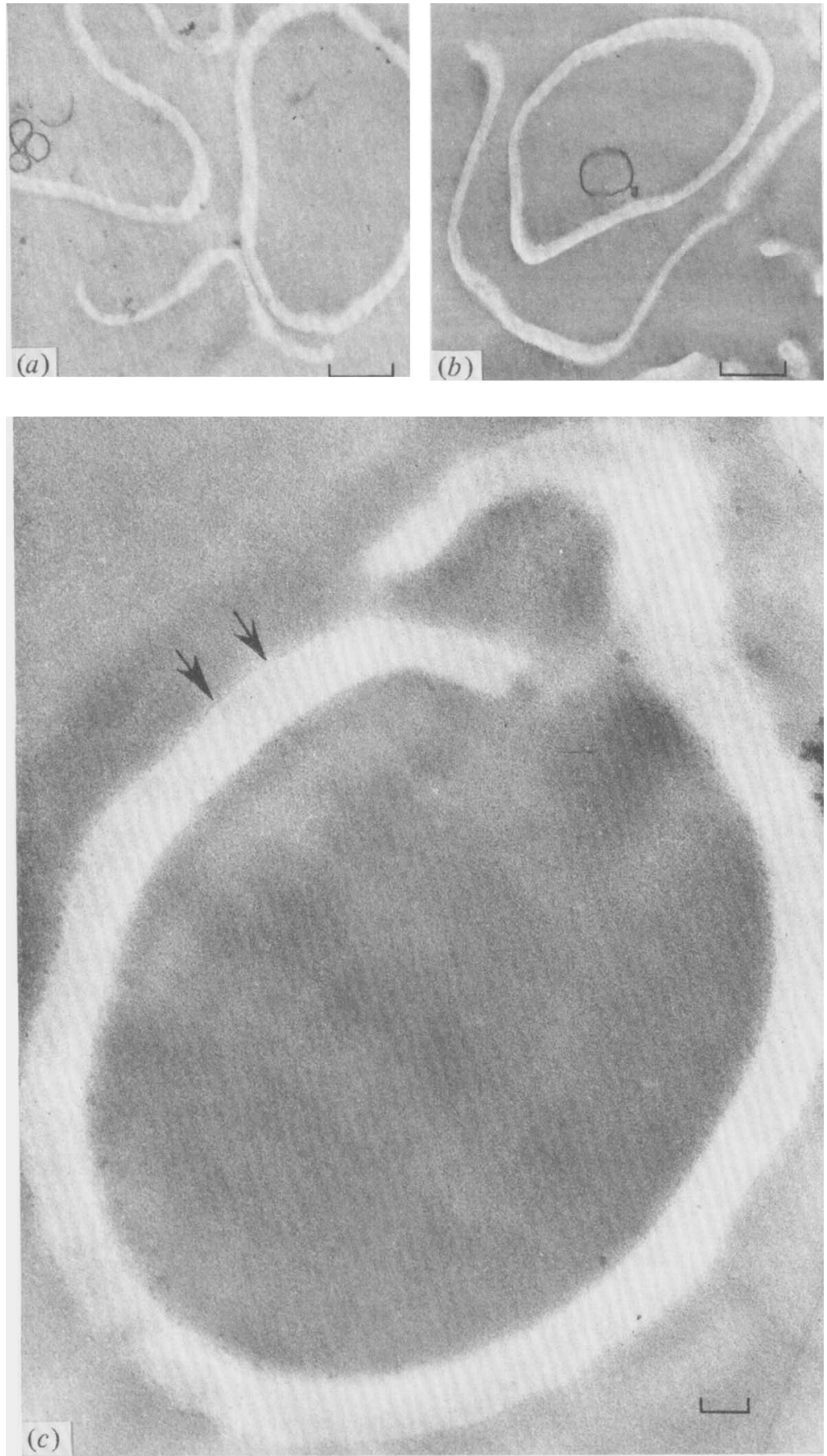

Fig. 3. Isolated and purified walls from exponential phase $(a)$, stationary phase $(b)$ and latestationary phase $(c)$ cultures. Note the absence, or the very scanty appearance, of electron-dense components at the outer wall surface (arrows in $c$ ). Very few membrane profiles are seen in $(a)$ and $(b)$. Sections were stained with lead citrate, uranyl acetate and lead citrate again for $15 \mathrm{~min}$ $(a), 45 \mathrm{~min}(b)$ or $30 \mathrm{~min}(c)$; due to this overstaining, the embedding plastic is electron-dense. Bar markers represent $500 \mathrm{~nm}(a, b)$ or $100 \mathrm{~nm}(c)$. 

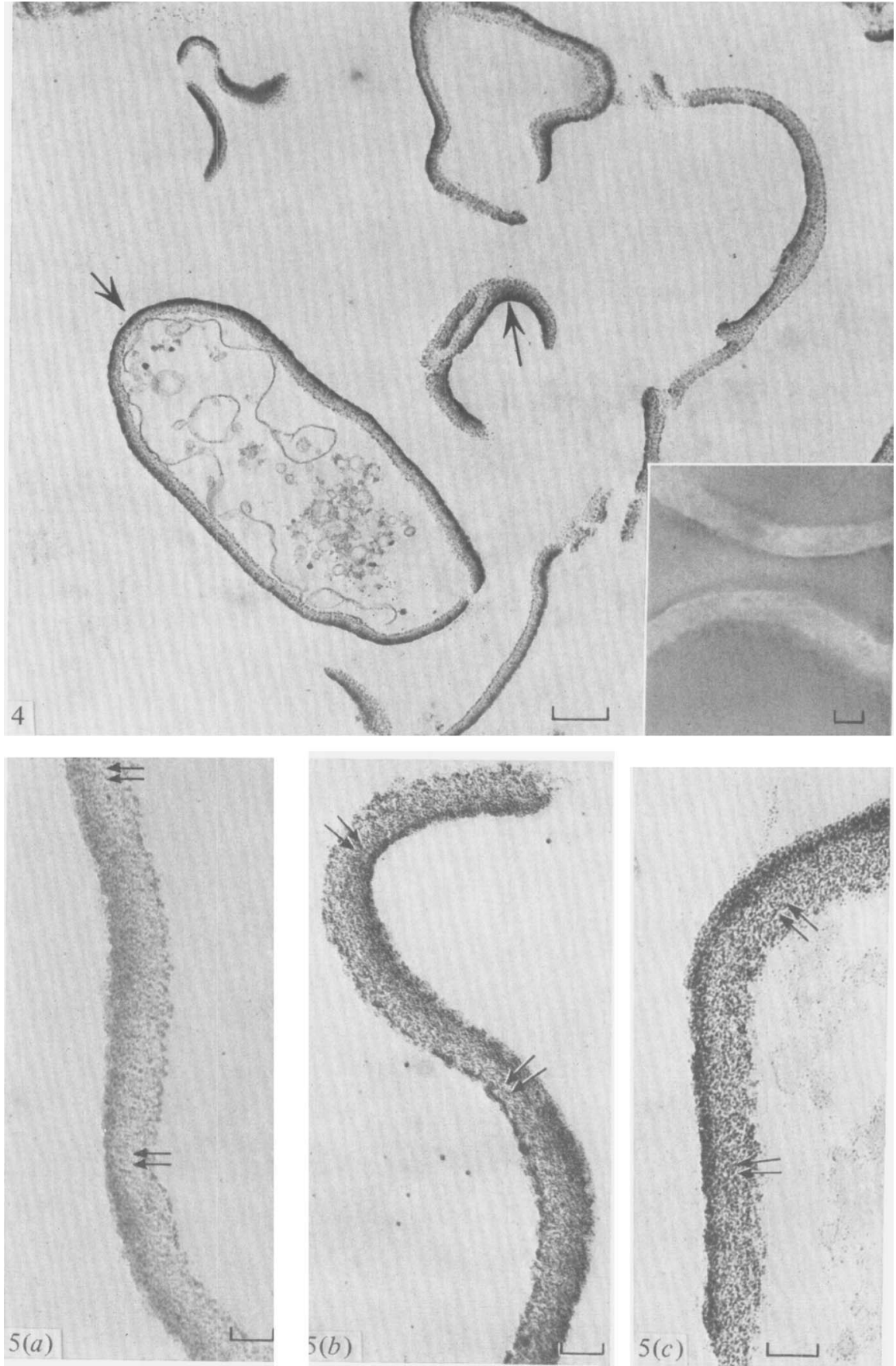

Fig. 4. Isolated walls from an exponential phase culture stained for polysaccharides by the method of Thiéry. Note the intense reaction of the outer wall region (arrows). The inset shows a control preparation in which the periodate oxidation step was omitted; walls had a similar appearance when the thiosemicarbazide treatment was omitted. Bar markers represent $500 \mathrm{~nm}$ and $100 \mathrm{~nm}$ (inset).

Fig. 5. Polysaccharide detection in isolated walls from exponential phase (a), early-stationary phase $(b)$ and late-stationary phase $(c)$ organisms. Note the more uniform reactivity in the inner region of the wall (arrows) as the cells progressed towards the late-stationary phase of growth (compare $a$ with $c$ ). Bar markers represent $100 \mathrm{~nm}$. 


\section{Table 1. Carbohydrate content of intact cells of Candida albicans}

The organisms were grown in YNBG at $37^{\circ} \mathrm{C}$ and after cessation of growth incubation was continued under the same conditions. The organisms were fractionated and carbohydrate was assayed as described in Methods. The figures in parentheses indicate the percentage composition.

\begin{tabular}{|c|c|c|c|c|c|}
\hline & \multicolumn{5}{|c|}{ Carbohydrate content $\left[\mu \mathrm{g}(\mathrm{mg} \text { dry wt })^{-1}\right]$} \\
\hline & Mannan & $\begin{array}{l}\text { Alkali- } \\
\text { soluble } \\
\text { glucan }\end{array}$ & $\begin{array}{l}\text { Acid- } \\
\text { soluble } \\
\text { glucan }\end{array}$ & $\begin{array}{l}\text { Insoluble } \\
\text { glucan }\end{array}$ & Total \\
\hline Exponentially growing organisms & $53(22)$ & $11(5)$ & $123(52)$ & $48(20)$ & 238 \\
\hline After $24 \mathrm{~h}$ starvation & $56(29)$ & $4(2)$ & $74(39)$ & $57(30)$ & 191 \\
\hline After $96 \mathrm{~h}$ starvation* & $51(29)$ & $7(4)$ & $68(37)$ & $58(31)$ & 184 \\
\hline
\end{tabular}

* Similar values were recorded after $144 \mathrm{~h}$ starvation.

correlate these changes with the carbohydrate composition of the various preparations. The one major change which occurred following the onset of starvation was a fall in the 'soluble glucan' fraction during the first $24 \mathrm{~h}$ after the cessation of growth. Thereafter the relative proportions of the carbohydrate constituents remained approximately constant up to $144 \mathrm{~h}$ starvation, although there was a slight decrease in the total carbohydrate on continued incubation (Table 1). Analysis of the carbohydrate composition of isolated purified walls from both exponentially growing and starved organisms demonstrated that, although the recovery of total carbohydrate was somewhat low $(67 \%$ for the exponential phase organisms and $75 \%$ for the stationary phase organisms), the relative ratios of the major constituents were approximately the same as in the intact cells and there was apparently no preferential loss of particular carbohydrates during the isolation and purification of the wall which might account for the different appearance of the wall in situ and in purified preparations.

\section{DISCUSSION}

The studies reported in this paper have clearly demonstrated that the wall of Candida albicans undergoes significant ultrastructural changes during continued incubation after the cessation of growth. Therefore there is a structural basis for the finding by Gale et al. (1975) that stationary phase organisms are more resistant to the polyene antibiotics than exponentially growing organisms and that this resistance is associated with the wall since protoplasts prepared from resistant cultures are sensitive. Hammond \& Kliger (1974) reported an increase in the thickness of the wall of $C$. albicans during ageing and this has been confirmed. There is, however, no direct relationship between the increase in thickness of the wall and the acquisition of resistance, since there was a 10-fold increase in resistance during the first $24 \mathrm{~h}$ and a 60 -fold increase in resistance after $72 \mathrm{~h}$ starvation during which time there was no appreciable change in the thickness of the wall. Only when organisms are resistant to AME at concentrations in excess of $20 \mu \mathrm{g} \mathrm{ml}^{-1}$ are the walls substantially thicker. There appears to be a better correlation between the development of resistance to polyene antibiotics and the changes in the ultrastructure of the wall, as exemplified by the loss of the layered appearance of the wall on continued incubation after the cessation of growth in a period corresponding to an increase in resistance from 10 -fold to more than 100 -fold. It should also be stressed that the recovery of antibiotic sensitivity following resuspension in a fresh nutrient medium is associated with the reappearance of the layered structure of the wall. Poulain et al. (1978) also reported a loss of some layered wall components, probably mannan-proteins, from the wall of $C$. albicans starved for 2 months.

There were no significant differences in appearance between the walls isolated from exponentially growing cultures and stationary phase cultures comparable to those observed in walls examined in situ. The profiles were significantly thinner than those observed in situ and had a rather dull, uniformly electron-transparent structure lacking any significant 
electron-dense components and layering. Some electron-dense material could be detected on the outermost surface of the wall after fixation and intense overstaining of the sections, but the slight differences that could be observed in some preparations could not be correlated with those observed in intact organisms. These ultrastructural observations are in accord with chemical analyses of isolated wall material which failed to demonstrate any significant difference in the gross chemical composition of the walls prepared from organisms harvested from exponential and stationary phase cultures (Kerridge et al., 1976).

One explanation of the apparent differences between the ultrastructure of walls in situ and walls purified by extensive washing after the organisms have been broken mechanically by shaking with glass beads is that certain of the wall constituents which are less firmly bound to the rigid glucan-chitin network are lost during the preparative procedure. Since the wall profiles remaining after ultrasonic disintegration of exponential phase organisms did retain some layered organization it would appear that it is not cell breakage per se which is responsible for the changed appearance but the technique employed for this purpose. Indeed, there is much circumstantial evidence for the loose binding of several 'plastic' components to the rigid glucan-chitin network of the wall (Kessler \& Nickerson, 1959; Chattaway et al., 1968; Mason, 1978). Recently, Nickerson \& Swaminathan (1977) emphasized the role of non-covalent, weak bonds in the overall wall organization of $C$. albicans. The electron-dense components responsible for the layering in the walls of Candida (and possibly other yeasts) have been shown to be alkali-soluble glucans and mannanproteins which are present in the periplasmic layer and also secreted through the wall (Cassone et al., 1978). These stainable constituents may represent a relatively small proportion of wall material, for instance the proteins which expose ionized groups reactive to ordinary fixatives and stains. Thus, loss of a few wall components may greatly change the ultrastructural pattern of the wall. In this connection it is of interest to note that the periplasmic layer was either greatly reduced or absent from the walls of organisms which had been subjected to prolonged starvation. If these constituents are important in the penetration of the polyene antibiotics through the wall of $C$. albicans it would not have been possible to detect them in wall preparations.

The reduction in both alkali- and acid-soluble glucans of intact organisms associated with the onset of starvation favours the idea that fewer 'plastic' wall components are present in the walls of stationary phase organisms. If this is so then the overall structure of the wall may be more tightly cross-linked in a network which includes all the major wall constituents without any significant spatial separation. This concept is supported by the more uniform reaction to the Thiéry cytochemical test exhibited by walls from stationary phase organisms which would indicate that the reactive $1,6-\beta$-glucan and mannan and unreactive 1,3- $\beta$-glucan and chitin are intermixed, and it must be emphasized that an increased cross-linking of the wall polysaccharide matrix can be achieved without gross changes in the chemical composition of the wall. It has not been possible in these studies to identify the precise changes in the structure and organization of the wall of $C$. albicans which are responsible for the phenotypic development of resistance to the polyene antibiotics. However they do demonstrate a structural basis for this phenomenon since the organization of the wall is significantly changed on prolonged incubation. The other important finding is that extreme caution must be observed in attempting to extrapolate results obtained with isolated purified walls to the structure and organization of the wall in intact organisms.

The authors wish to thank the Medical Research Council for financial support and $\mathrm{Mr}$ L. Jewitt and Mr M. Mari for their assistance in the preparation of the electron micrographs. A.C. is also indebted to Professor D. H. Northcote (Department of Biochemistry, University of Cambridge) for use of the electron microscopic facilities of the Plant Biochemistry Laboratory. 


\section{REFERENCES}

Cassone, A., Simonetti, N. \& Strippoli, V. (1972). Studi ultrastrutturali sulla formazione di tubi germinativi in Candida albicans. Atti XVI Congresso della Societa Italiana di Microbiologia, Pisa, vol. 2, pp. 227-233.

Cassone, A., Simonet'ti, N. \& Strippoli, V. (1973). Ultrastructural changes in the wall during germtube formation from blastospores of Candida albicans. Journal of General Microbiology 77, 417-426.

Cassone, A., Mattia, E. \& Boldrini, L. (1978). Agglutination of blastospores of Candida albicans by Concanavalin $\mathrm{A}$ and its relationship with the distribution of mannan polymers and the ultrastructure of the cell wall. Journal of General Microbiology 105, 263-273.

Chattaway, F. W., Holmes, M. R. \& Barlow, A. J. E. (1968). Cell wall composition of mycelial and blastospore forms of Candida albicans. Journal of General Microbiology 51, 367-376.

Chattaway, F. W., Shenolikar, S., O'Reilly, J. \& BARLow, A. J.E. (1976). Changes in the cell surface of the dimorphic forms of Candida albicans by treatment with hydrolytic enzymes. Journal of General Microbiology 95, 335-347.

GaLe, E. F. (1974). The release of potassium ions from Candida albicans in the presence of polyene antibiotics. Journal of General Microbiology 80, 451-465.

Gale, E. F., Johnson, A. M., Kerridge, D. \& KoH, T. Y. (1975). Factors affecting the changes in amphotericin sensitivity of Candida albicans during growth. Journal of General Microbiology 87, 20-36.

Gale, E. F., Johnson, A. M. \& Kerridge, D. (1977). The effect of aeration and metabolic inhibitors on resistance to amphotericin in starved cultures of Candida albicans. Journal of General Microbiology 99, 77-84.

Hammond, S. M. \& KLiger, B. N. (1974). Studies on the role of the cell wall of Candida albicans in the mode of action of polyene antibiotics. Proceedings of the Society for General Microbiology 1, 45 .

Herbert, D., Phipps, P. J. \& Strange, R. E. (1971).
Chemical analysis of microbial cells. Methods in Microbiology 5B, 209-344.

Johnson, B., White, R. J. \& Williamson, G. M. (1978). Factors influencing the susceptibility of Candida albicans to the polyenoic antibiotics nystatin and amphotericin B. Journal of General Microbiology 104, 325-333.

Kerridge, D., KoH, T. Y., MarriotT, M. S. \& Gale, E. F. (1976). The production and properties of protoplasts from the dimorphic yeast Candida albicans. In Microbial and Plant Protoplasts, pp. 23-38. Edited by J. F. Peberdy, A. H. Rose, H. J. Rogers \& E. C. Cocking. London and New York: Academic Press.

Kessler, G. \& Nickerson, W. J. (1959). Glucomannan-protein complexes from cell walls of yeasts. Journal of Biological Chemistry 234, 22812285.

MASON, R. E. (1978). The mode of action of echinocandin. Ph.D. thesis, University of Cambridge.

Nickerson, W. J. \& Swaminathan, V. (1977). Linkages in cell walls of yeasts. In Second International Mycological Congress (Tampa, Florida, U.S.A.) Abstracts, vol. M-Z, p. 476.

Poulain, D., Tronchin, G., Dubremetz, J. F. \& BigueT, J. (1978). Ultrastructure of the cell wall of Candida albicans blastospores: study of its constitutive layers by the use of a cytochemical technique revealing polysaccharides. Annales de Microbiologie (Institut Pasteur) 129, 141-153.

Reynolds, E.S. (1963). The use of lead citrate at high $\mathrm{pH}$ as an electron-opaque stain in electron microscopy. Journal of Cell Biology 17, 208-212.

Spurr, A. R. (1969). A low-viscosity epoxy resin embedding medium for electron microscopy. Journal of Ultrastructure Research 26, 31-38.

ThIÉRY, J. P. (1967). Mise en évidence des polysaccharides sur coupes fines en microscopie électronique. Journal de Microscopie 6, 987-1018.

Trevelyan, W. E. \& Harrison, J.S. (1956). Studies on yeast metabolism. Yeast carbohydrate fractions, separation from nucleic acid, analysis and behaviour during anaerobic fermentation. Biochemical Journal 63, 23-33. 